\title{
openheart Does postoperative cognitive decline after coronary bypass affect quality of life?
}

\author{
Fredrike Blokzijl (D) , ${ }^{1}$ Frederik Keus, ${ }^{2}$ Saskia Houterman, ${ }^{3}$ Willem Dieperink, ${ }^{2}$ \\ Iwan C C van der Horst, ${ }^{4}$ Michiel F Reneman, ${ }^{5}$ Anthony R Absalom, ${ }^{6}$ \\ Massimo A Mariani ${ }^{1}$
}

- Additional supplemental material is published online only. To view, please visit the journal online (http://dx.doi.org/10. 1136/openhrt-2020-001569).

To cite: Blokzijl F, Keus F, Houterman S, et al. Does postoperative cognitive decline after coronary bypass affect quality of life?. Open Heart 2021;8:e001569. doi:10.1136/ openhrt-2020-001569

Received 5 January 2021 Revised 12 February 2021 Accepted 6 April 2021

Check for updates

C Author(s) (or their employer(s)) 2021. Re-use permitted under CC BY. Published by BMJ.

${ }^{1}$ Department of Cardiothoracic Surgery, University Medical Centre Groningen, Groningen, The Netherlands

${ }^{2}$ Department of Critical Care, University Medical Centre Groningen, Groningen, The Netherlands

${ }^{3}$ Department of Education and Research, Catharina Hospital, Eindhoven, The Netherlands ${ }^{4}$ Department of Intensive Care, Maastricht University Medical Centre, Maastricht, The Netherlands

${ }^{5}$ Department of Rehabilitation Medicine, University Medical Centre Groningen, Groningen, The Netherlands

${ }^{6}$ Department of Anesthesiology, University Medical Centre Groningen, Groningen, The Netherlands

Correspondence to Dr Fredrike Blokzijl; f.zwiersblokzij|@umcg.nl

\section{ABSTRACT}

Objective This study aimed to explore the influence of coronary artery bypass grafting (CABG) on both postoperative cognitive dysfunction and quality of life (QoL) and the association between the two patient-related outcomes.

Methods In a prospective, observational cohort study, patients with elective, isolated CABG were included. Cognitive function was assessed using the Cogstate computerised cognitive test battery preoperatively, 3 days and 6 months after surgery. QoL was measured preoperatively and at 6 months using the RAND-36 questionnaire including the Physical Component Score (PCS) and the Mental Component Score (MCS). Regression analysis, with adjustment for confounders, was used to evaluate the association between postoperative cognitive dysfunction and QoL.

Results A total of 142 patients were included in the study. Evidence of persistent cognitive dysfunction was observed in $33 \%$ of patients after 6 months. At 6 months, the PCS had improved in $59 \%$ and decreased in $21 \%$ of patients, and the MCS increased in $49 \%$ and decreased in $29 \%$. Postoperative cognitive changes were not associated with QoL scores.

Conclusions Postoperative cognitive dysfunction and decreased QoL are common 6 months after surgery, although cognitive function and QoL were found to have improved in many patients at 6 months of follow-up. Impaired cognitive function is not associated with impaired QoL at 6 months.

Trial registration number NCT03774342.

\section{INTRODUCTION}

In the past few decades, improvements in operative techniques and perioperative care have led to a steady decline in mortality after cardiac surgery. Although survival rates have improved, elderly patients are at increased risk of postoperative complications such as neurological and pulmonary problems. $^{1}{ }^{2}$ Neurological complications after cardiac surgery have been classified by the American College of Cardiology and the American Heart Association into two categories. ${ }^{3}$ Type I deficits result from well-defined

\section{Key questions}

What is already known about this subject?

- Postoperative cognitive dysfunction (POCD) is a common neurocognitive disorder with an incidence of $30 \%-60 \%$ after coronary artery bypass grafting. Despite the high incidence of POCD, the effect of POCD on patients' daily lives after coronary bypass has not yet been investigated.

What does this study add?

- This study showed that most patients benefit in terms of an increased quality of life (QoL) and recovery of cognitive functioning 6 months after surgery. However, long-term POCD was still present in one out of three patients and QoL was not yet at the preoperative level in a large proportion of patients 6 months after surgery. Impaired cognitive function was not associated with impaired QoL.

How might this impact on clinical practice?

- These findings enable healthcare workers to tailor the care and guidance of patients during the process of shared decision making prior to surgery. Patients' preferences and expectations on postoperative recovery need to be discussed thoroughly during the preoperative phase. Studies on patientrelated outcomes can be valuable during this counselling process.

local or regional insults resulting in transient ischaemic attack (TIA), stroke, coma and fatal brain injury. Type II deficits result from more diffuse and poorly understood insults, and include delirium and postoperative cognitive dysfunction (POCD). Delirium is clearly defined in the Diagnostic and Statistical Manual for Mental Disorders, Fifth Edition. ${ }^{4}$ In contrast, the definition and operationalisation of POCD is less clear; it is mostly described as a deficit of concentration, attention, memory and motor speed that lasts for several weeks or months. ${ }^{3}$ Recently, an expert working group produced a set of recommendations for diagnosis and nomenclature 
for postoperative neurocognitive disorders to align the terminology used with that of the DSM-V. ${ }^{5}$ They recommended that the term POCD be used for mild or major neurocognitive disorders found to be present between 1 and 12 months after surgery. Studies of patients who have undergone coronary artery bypass grafting (CABG) describe an incidence of POCD of 30\%-60\% depending on the timing, type and interpretation of cognitive tests used, and the patient population involved. ${ }^{67}$ Despite this high incidence and the fact that in vulnerable elderly patients even a small decline may have important consequences such as loss of independence, ${ }^{89}$ data on the impact of POCD on quality of life (QoL) are scarce. The primary aim of this study was to explore the influence of CABG on cognitive function and QoL, and the secondary aim was to investigate the association between POCD and QoL in adult patients after CABG.

\section{METHODS}

We conducted a prospective single-centre cohort study. The study protocol is registered at ClinicalTrials.gov. This article describes the cognitive outcomes of our study population in relation to QoL; outcomes on physical performance, as described in the study protocol, will be reported in another article. The study results are reported according to the Strengthening the Reporting of Observational Studies in Epidemiology guidelines ${ }^{10}$ (online supplemental material S1).

\section{Eligibility criteria}

We included adult patients admitted for elective, solitary on-pump CABG in the University Medical Centre Groningen, the Netherlands. Exclusion criteria were previous cardiac surgery and combined surgery (due to the increased risks of complications), pre-existing neurological deficits (ie, dementia, stroke and epilepsy) and psychiatric illness limiting reliability of screening tests. If patients were likely to experience difficulty completing cognitive testing due to impaired eyesight or hearing, or problems understanding the Dutch language, they were also excluded from the study.

\section{Procedures}

On the day of admission, usually the day before surgery, patients were identified and contacted for informed consent by the attending doctor or nurse practitioner. After informed consent was obtained, patients were included and baseline preoperative measurements were obtained. Postoperative assessment of cognitive function was performed in the hospital 3 days after surgery (short term) and at the patients' homes 6 months after surgery (long term). QoL was measured at baseline and 6 months after surgery.

\section{Demographic and medical characteristics}

Baseline demographic data were retrieved from the electronic patient medical records and included age, sex, Body Mass Index, education level (low: primary school; moderate: high school or secondary vocational education; high: college (applied sciences) or university), EuroSCORE I and II, and the presence of comorbidity such as diabetes, ${ }^{11}$ pulmonary disease, ${ }^{11}$ arterial vascular disease, ${ }^{11}$ renal disease ${ }^{12}$ and impaired ventricular function. ${ }^{13}$ Definitions of comorbidities are included in online supplemental material S2. Perioperative data included duration of surgery, time of cardiopulmonary bypass, cross-clamp time (in minutes) and the number of (arterial) grafts.

\section{Outcome measures}

Cognitive function was assessed using the Cogstate brief computerised cognitive test battery (Cogstate, Melbourne, Australia). The test battery we used consisted of four tasks: the detection task, the identification task, the one card learning task and the one back task (ONB), assessing psychomotor speed, selective attention, visual learning and working memory, respectively. ${ }^{14}$ The Cogstate tests have been used in several other studies, indicating a good sensitivity for detecting subtle changes in cognitive performance and strong test-retest reliability. ${ }^{14} 15$ On the day before surgery, the tests were performed twice as recommended by the software vendor. The first was to minimise practice effects and the second was used as baseline test. Before starting, each task was introduced by the researcher using standardised written instruction. Each set of four tests required approximately $20 \mathrm{~min}$ to complete. All cognitive function scores were standardised according to normative data from age-matched controls. ${ }^{16}$ A standardised score higher than 100 indicated a better than average score compared with the age-matched population. ${ }^{17}$ As suggested by Evered et $a l,{ }^{5}$ signs of cognitive dysfunction 3 days after surgery were interpreted as delayed neurocognitive recovery effected by drugs, anaesthesia and/or pain with the potential for recovery.

To perform a within-subject analysis a standardised reliable change Z-score for each postoperative cognitive test was calculated, based on the difference between the postoperative and baseline score, and normalised using test-retest variability data provided by the software vendor. ${ }^{18}$ The standardised change Z-scores of all four individual tasks were summed to generate a composite Z-score. ${ }^{7}$ POCD was operationally defined as a Z-score of $<-2$ in two or more individual tasks or a composite Z-score of $<-2 .{ }^{18}$ This threshold of $<-2$ was chosen to provide consistency with the suggestion of the expert working party of defining POCD as equivalent to major neurocognitive disorder if the decline in test scores is $>2$ SDs. $^{5}$

QoL was measured using the RAND-36 V.2 questionnaire. The questionnaire is a widely used and validated instrument containing eight health domains: physical functioning, social functioning, role limitations due to physical health problems, role limitations due to emotional problems, mental health, vitality, pain and general health perception. ${ }^{19}$ Each dimension is scored 
on a scale between 0 and 100; a higher score is equivalent to better health. Two summarised scores were calculated: a Physical Component Score (PCS) and a Mental Component Score (MCS). We considered a minimal clinically important difference to be 5 points and calculated the change in QoL for each patient between preoperative and postoperative measurements. QoL was judged as being improved ( $>5$ points), worse $(<5$ points) or unchanged ( $\leq 5$ points decrease or increase in score). ${ }^{11}$ Secondary outcomes were postoperative complications including delirium, ${ }^{20}$ atrial fibrillation, ${ }^{21}$ myocardial infarction, ${ }^{22}$ surgical re-exploration, ${ }^{11}$ deep sternal wound infection ${ }^{11}$ and renal failure, ${ }^{11}$ all within 30 days after surgery and stroke/ TIA within 72 hours after surgery. ${ }^{23}$ Definitions of complications are included in online supplemental material S2. Additional outcomes were duration of stay at the intensive care unit (ICU) and discharge destination.

\section{Data analysis}

The sample size calculation was based on the hypothetical association between POCD and QoL. POCD was assumed to be the independent variable and QoL as the dependent variable. A previous study on patients with POCD after CABG reported an SD of $8.5^{17}$ and a study on QoL after cardiac events reported an SD of $11 .{ }^{24}$ A sample size of 123 patients was required for a two-tailed test at a minimal detectable difference of 0.33 , an $\alpha$ of 0.05 and power of $80 \%$ to detect an association between POCD and QoL. To account for missing data, we included 142 patients.

Characteristics of patients are presented as numbers (with percentages) for dichotomous variables and as means (with SD) or medians (with IQRs) for continuous variables depending on distributions. Differences between baseline and 6 months of follow-up of cognitive function and QoL were tested using paired t-tests. Differences in baseline, operative and postoperative characteristics between the patients with and without POCD were tested using the $\chi^{2}$ or Fisher's exact test. Linear regression analysis was used to evaluate the impact of POCD on the difference in QoL (dependent variable). Possible risk factors for POCD based on literature, as well as age and baseline PCS/MCS, were included in the multivariable model. All analyses were tested two-sided, and tests with $p$ values of $<0.05$ were considered statistically significant. All data were analysed using SPSS V.25.0.

\section{RESULTS}

A total of 142 patients undergoing elective CABG were enrolled between October 2018 and July 2019 (online supplemental material S3). Table 1 presents all baseline, operative and postoperative characteristics. Based on the standardised composite Z-score at baseline, two patients already had mild cognitive impairment based on a composite Z-score of $>1$ SD preoperatively.
Table 1 Baseline, operative and postoperative characteristics of patients with $\mathrm{CABG}$

$n=142$

\begin{tabular}{ll}
\hline Baseline characteristics & \\
Sex (female) & $18(13)$ \\
Age (years), mean (SD) & $64.3(9.4)$ \\
BMI $\left(\mathrm{kg} / \mathrm{m}^{2}\right)$ & \\
$<25$ & $34(24)$ \\
$25-30$ & $71(50)$ \\
$>30$ & $37(26)$ \\
$\quad$ Log EuroSCORE I, median (IQR) & $2.7(1.9-4.7)$ \\
In groups &
\end{tabular}

$\begin{array}{ll}<10 \% & 133(94) \\ 10 \%-20 \% & 9(6.3) \\ >20 \% & 0(0.0) \\ \text { EuroSCORE II, median (IQR) } & 1.5(1.1-2.2) \\ \text { Diabetes mellitus } & 31(22) \\ \text { Pulmonary disease } & 15(11) \\ \text { Arterial vascular disease } & 7(4.9) \\ \text { Renal disease } & 14(9.9) \\ \text { LVEF } & \\ >50 \% & 96(68) \\ 30 \%-50 \% & 45(32) \\ <30 \% & 1(0.7) \\ \text { Education level } & \\ \text { Low } & 40(28) \\ \text { Moderate } & 55(39) \\ \text { High } & 46(33)\end{array}$

Operative characteristics
Number of grafts

Number of grafts

\begin{tabular}{|ll|}
\hline One graft & $1(0.7)$ \\
\hline Two grafts & $139(98)$ \\
\hline Three grafts & $2(1.4)$ \\
\hline Number of arterial grafts & \\
\hline Use of one arterial graft & $100(70)$ \\
\hline Use of two or more arterial grafts & $39(27)$ \\
\hline No arterial graft & $3(2.1)$ \\
\hline Surgical time, $†$ mean (SD) & $254(41)$ \\
\hline CPB time, $†$ mean (SD) & $106(30)$ \\
\hline Cross-clamp time, $†$ mean (SD) & $64(22)$ \\
\hline Postoperative characteristics & \\
\hline Delirium & $7(4.9)$ \\
\hline Atrial fibrillation & $14(9.9)$ \\
\hline Myocardial infarction & $2(1.4)$ \\
\hline Surgical re-exploration & $3(2.1)$ \\
\hline Deep sternal wound infection & $3(2.1)$ \\
\hline Stroke/TIA & $0(0.0)$ \\
\hline
\end{tabular}




\begin{tabular}{ll}
\hline Table $1 \quad$ Continued & \\
\hline & $\mathbf{n}=142$ \\
\hline Renal failure & $0(0.0)$ \\
ICU stay, $\ddagger$ median (IQR) & $21(18-25)$ \\
Discharge destination & \\
Home & $99(71)$ \\
Other hospital & $21(15)$ \\
Rehabilitation centre & $18(13)$ \\
Nursing home & $1(0.7)$ \\
\hline
\end{tabular}

Values are presented as $n(\%)$ unless otherwise indicated.

*Education level for one patient unknown.

†Surgical time, CPB time and cross-clamp time in minutes. fICU stay in hours.

BMI, Body Mass Index; CABG, coronary artery bypass grafting; CPB, cardiopulmonary bypass; ICU, intensive care unit; LVEF, left ventricular ejection fraction; TIA, transient ischaemic attack.

Short-term postoperative cognitive tests were performed after a median of 3 days (range 3-7) after surgery. Three patients refused further participation, and five patients were unable to complete the early postoperative test due to pain or dizziness during testing (three patients), a prolonged stay in the ICU (one patient) and transfer to another hospital on day 3 (one patient). Among the remaining 134 patients, 80 patients $(60 \%)$ fulfilled the criteria for early cognitive dysfunction 3 days after surgery, based on delayed neurocognitive recovery in the terminology suggested by Evered et al. ${ }^{5}$ Two patients died during follow-up; one patient moved abroad; and five patients refused further participation. Long-term cognitive tests were performed in 131 patients after a median of 192 days (range 177-219) after surgery. Forty-three patients $(33 \%)$ had cognitive dysfunction at long-term follow-up. Twenty-nine patients $(22 \%)$ showed improved cognitive function with $\mathrm{a}>2$ increase in their cognitive function scores compared with baseline scores. Figure 1 shows the composite standardised cognitive change scores measured at 3-7 days and 6 months after surgery. The mean cognitive test scores are presented in online supplemental material S4.

\section{Quality of life}

At 6 months of follow-up, PCS was increased ( $>5$ points) in $59 \%$ of the patients and decreased ( $>5$ points) in $21 \%$. MCS was increased in $49 \%$ of the patients and decreased in 29\% (figure 2). The mean MCS, PCS and subscale scores are presented in online supplemental material S5.

\section{Association between postoperative cognitive dysfunction and QoL}

Table 2 shows the results of the regression analysis. Associations between POCD and difference in QoL 6 months after surgery were non-significant (PCS $\mathrm{p}=0.66$ and MCS $\mathrm{p}=0.91$, respectively). The association between age and PCS did not reach statistical significance $(p=0.06)$. In the multivariable analysis,

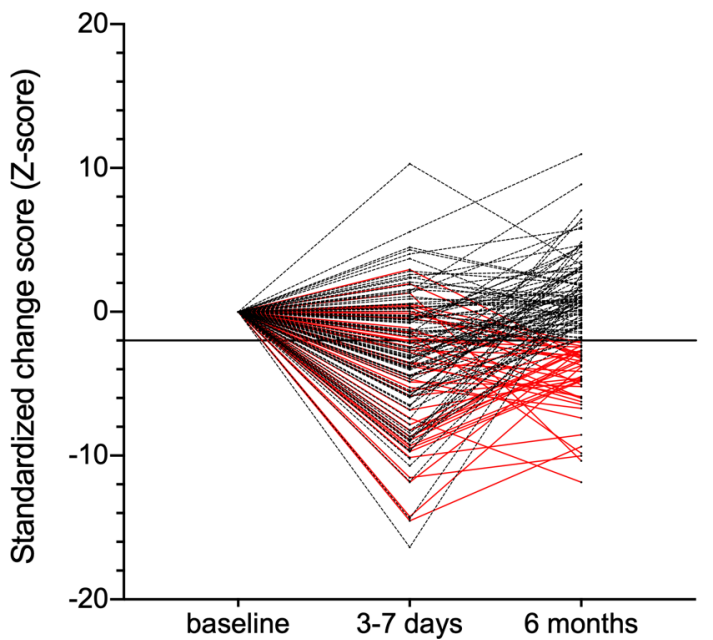

Figure 1 Development of the composite standardised cognitive change scores per patient over time. Red solid lines indicate patients who had Z-scores below -2 at 6 months. Black dashed lines indicate patients who had a Z-score above -2 at 6 months of follow-up.

baseline PCS and education level were statistically significantly correlated with difference in PCS at 6 months of follow-up. Baseline MCS was associated with the difference in MCS 6 months after CABG.

\section{Patients with and without POCD at 6 months of follow-up}

Of 80 patients with POCD at short-term follow-up, 37 $(46 \%)$ recovered their cognitive dysfunction 6 months after surgery. Forty-three patients (54\%) were classified as having persistent POCD at long-term follow-up. Baseline characteristics, operative characteristics and postoperative complications of patients with and without POCD at 6 months after surgery are presented in table 3. Age $(\mathrm{p}=0.040)$, education level $(\mathrm{p}=0.046)$ and postoperative delirium $(\mathrm{p}=0.015)$ were different between the groups. Differences in PCS and MCS between the groups were not statistically significant (online supplemental material S6).

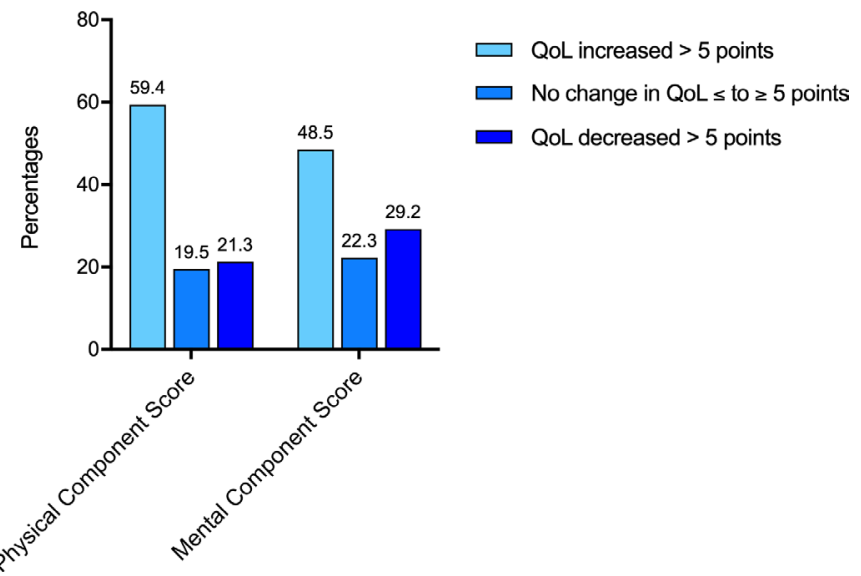

Figure 2 Differences between baseline and 6 months follow-up in the QoL of patients with coronary artery bypass grafting: Physical Component Score and Mental Component Score; cut-off value: 5 points. QoL, quality of life. 
Table 2 Univariable and multivariable linear regression models of the effect of preoperative and postoperative factors on the difference in quality of life 6 months after coronary artery bypass grafting

\begin{tabular}{|c|c|c|c|c|c|c|}
\hline \multirow{3}{*}{$\begin{array}{l}\text { Univariable analysis } \\
\text { PCS }\end{array}$} & \multirow[b]{3}{*}{ Beta } & \multirow[b]{3}{*}{$95 \% \mathrm{Cl}$} & \multirow[b]{3}{*}{$P$ value } & \multicolumn{3}{|c|}{ Multivariable analysis } \\
\hline & & & & \multicolumn{2}{|l|}{ PCS } & \multirow{2}{*}{$\begin{array}{l}R^{2}=0.42 \\
\text { value }\end{array}$} \\
\hline & & & & Beta & $95 \% \mathrm{Cl}$ & \\
\hline POCD Z-score at 6 months & 0.20 & -0.68 to 1.07 & 0.66 & 0.18 & -0.53 to 0.88 & 0.62 \\
\hline Age & -0.35 & -0.71 to 0.02 & 0.06 & -0.23 & -0.52 to 0.07 & 0.13 \\
\hline Baseline PCS & -0.59 & -0.73 to -0.45 & $<0.001$ & -0.59 & -0.73 to -0.45 & $<0.001$ \\
\hline Baseline cognitive functioning & 7.83 & -19.8 to 35.1 & 0.57 & 6.99 & -15.3 to 29.3 & 0.54 \\
\hline Education level & 4.50 & 0.17 to 8.84 & 0.04 & 5.00 & 1.52 to 8.48 & 0.05 \\
\hline Delirium & 3.72 & -12.3 to 19.8 & 0.65 & -4.06 & -17.5 to 9.45 & 0.55 \\
\hline \multirow[t]{2}{*}{ MCS } & & & & MCS & & $R^{2}=0.28$ \\
\hline & Beta & $95 \% \mathrm{Cl}$ & $P$ value & Beta & $95 \% \mathrm{Cl}$ & $P$ value \\
\hline POCD Z-score at 6 months & 0.03 & -0.71 to 0.76 & 0.94 & -0.18 & -0.85 to 0.50 & 0.61 \\
\hline Age & -0.10 & -0.41 to 0.21 & 0.52 & 0.06 & -0.23 to 0.34 & 0.69 \\
\hline Baseline MCS & -0.41 & -0.53 to -0.29 & $<0.001$ & -0.43 & -0.56 to -0.30 & $<0.001$ \\
\hline Baseline cognitive functioning & -0.99 & -32.1 to 14.1 & 0.44 & -1.99 & -23.4 to 19.4 & 0.86 \\
\hline Education level & 0.16 & -3.52 to 3.84 & 0.93 & 0.60 & -2.69 to 3.89 & 0.72 \\
\hline Delirium & 3.78 & -9.78 to 17.3 & 0.58 & -5.00 & -18.0 to 7.97 & 0.45 \\
\hline
\end{tabular}

MCS, Mental Component Score; PCS, Physical Component Score; POCD, postoperative cognitive dysfunction.

\section{DISCUSSION}

In this prospective cohort study, we observed that many patients showed a postoperative improvement in cognitive function, and in the physical and mental component of QoL. However, POCD was persistent in 33\% of patients 6 months after surgery, and there was either no change or a decline in QoL in approximately half of all patients. Contrary to our expectations, we did not find an association between POCD and difference in QoL at 6 months after CABG. A possible explanation could be that people with impaired cognitive function can still experience a high QoL. Alternatively, patients may adjust their perceived level of QoL (glad to be alive), so that the difference between the new and the intended level is normalised after surgery.

Many studies have been performed on POCD after CABG, mostly addressing the incidence and aetiology of POCD. ${ }^{6} 1725$ The difficulty with studies on POCD are the lack of universally accepted definitions and gold standards for measuring POCD, sometimes leading to conflicting results. ${ }^{69}$ As in other POCD studies, we used the reliable change index that relates the change of scores to the normal test-retest variation in an age-matched control group. 7171825 Other commonly used statistical methods are an absolute decline (usually $>1$ SD calculated from preoperative scores) or a percentage change from baseline (usually a decline of $>20 \%$ ). However, these methods do not relate to data from age-matched controls and therefore do not account for normal variability among a population. ${ }^{26}$ Recommendations about thresholds are published by the expert working group, but they do not recommend specific tests. ${ }^{5}$ The Cogstate test battery may be suitable as standard instrument because the major strength of this instrument is the comparability of retrieved data to data from age-matched controls. Also, several studies suggest this instrument to be both sensitive and reliable. ${ }^{14-16}$

The high number of patients in our study not improving after $\mathrm{CABG}$ indicates that CABG may have a high impact on patients' QoL, as suggested by other studies. ${ }^{27} 28$ The long-term incidence of POCD in our study is also rather high, which is in line with other studies. ${ }^{6}$ Possible explanations for POCD include perioperative factors (ie, low blood pressure leading to altered cerebral perfusion, cerebral microemboli caused by disruption of aortic atherosclerotic plaques, anaesthesia and systemic inflammatory response) and patient-related factors (ie, systemic atherosclerosis and decline in cognitive performance caused by altered age). Current evidence suggests that on-pump and off-pump CABG procedures have similar long-term cognitive outcomes. ${ }^{62529}$ One possible explanation is that some patients already have microinfarcts before surgery and another is that both CABG techniques cause new microinfarcts during surgery that are silent (ie, do not cause overall neurological deficits) but are sufficient to cause POCD. Studies to investigate this hypothesis could use diffusion-weighted MRI imaging before and after surgery to evaluate the correlation between microinfarct load and cognitive outcome.

Other explanations for the long-term decline in QoL and the high incidence of long-term POCD could be side effects of surgery (ie, new comorbidities or reduced independence) or other confounding factors unrelated to the intervention. Perhaps future studies 


\begin{tabular}{|c|c|c|c|c|c|c|c|}
\hline \multicolumn{4}{|l|}{6 months after CABG } & & \multirow{2}{*}{$\begin{array}{l}\text { No POCD } \\
(n=88)\end{array}$} & \multirow{2}{*}{$\begin{array}{l}\text { POCD } \\
(n=43)\end{array}$} & \multirow[b]{2}{*}{$P$ value } \\
\hline & No POCD & POCD & Rulun & & & & \\
\hline & & & & ICU stay†, median (IQR) & $21(18-25)$ & $21(17-23)$ & 0.25 \\
\hline Baseline characteristics & & & & \multirow{2}{*}{ Discharge destination } & & & 0.99 \\
\hline Sex (female) & $10(11)$ & $5(12)$ & $>0.99$ & & $63(72)$ & $31(72)$ & \\
\hline Age (years), mean (SD) & $63(9.2)$ & $67(9.0)$ & 0.040 & \multirow{3}{*}{$\begin{array}{l}\text { Home } \\
\text { Other hospital } \\
\text { Rehabilitation centre } \\
\text { Nursina home }\end{array}$} & $12(14)$ & $6(14)$ & \\
\hline $\mathrm{BMI}\left(\mathrm{kg} / \mathrm{m}^{2}\right)$ & & & 0.29 & & $12(14)$ & & \\
\hline$<25$ & $18(20)$ & $13(30)$ & & & $\begin{array}{l}12(14) \\
0(0.0)\end{array}$ & $\begin{array}{l}6(14) \\
0(0.0)\end{array}$ & \\
\hline
\end{tabular}

$\begin{array}{lll}>30 & 49(56) & 18(42) \\ & 21(24) & 12(28)\end{array}$

Log EuroSCORE I, median $\quad 2.6(1.5-4.4) \quad 3.6(2.1-5.3) \quad 0.72$ (IQR)

In groups

\begin{tabular}{|llll}
\hline$<10 \%$ & $83(94)$ & $40(93)$ & 0.15 \\
\hline $10 \%-20 \%$ & $5(6.0)$ & $3(7.0)$ & \\
\hline EuroSCORE II, median (IQR) & $1.5(1.1-2.2)$ & $1.5(1.1-2.5)$ & 0.71 \\
\hline Diabetes mellitus & $20(2.3)$ & $9(20.9)$ & 0.79 \\
\hline Pulmonary disease & $7(8.0)$ & $7(16.3)$ & 0.23 \\
\hline Arterial vascular disease & $4(4.5)$ & $3(7.0)$ & 0.68 \\
\hline Renal disease & $8(9.1)$ & $5(11.6)$ & 0.76 \\
\hline LVEF & & & 0.54 \\
\hline$>50 \%$ & $58(66)$ & $33(36)$ & \\
\hline $30 \%-50 \%$ & $29(33)$ & $10(23)$ & \\
\hline$<30 \%$ & $1(1.1)$ & $0(0.0)$ & \\
\hline Education level & & & 0.046 \\
\hline Low & $27(31)$ & $9(21)$ & \\
\hline Moderate & $39(44)$ & $14(33)$ & \\
\hline High & $22(25)$ & $20(46)$ & \\
\hline Baseline PCS, mean (SD) & $65(20)$ & $63(19)$ & 0.46 \\
\hline Baseline MCS, mean (SD) & $71(20)$ & $73(21)$ & 0.51 \\
\hline Cognitive test results, mean (SD) & & \\
\hline DET & $101(6.7)$ & $103(5.3)$ & 0.24 \\
\hline IDN & $100(4.9)$ & $101(4.9)$ & 0.69 \\
\hline OCL & $104(8.7)$ & $104(8.4)$ & 0.71 \\
\hline ONB & $98(5.6)$ & $98(6.1)$ & 0.49 \\
\hline Operative characteristics & & & \\
\hline Surgical time, ${ }^{*}$ mean (SD) & $257(46)$ & $249(33)$ & 0.24 \\
\hline CPB time, ${ }^{*}$ mean (SD) & $108(32)$ & $101(24)$ & 0.21 \\
\hline $\begin{array}{l}\text { Cross-clamp time, }{ }^{*} \text { mean } \\
\text { (SD) }\end{array}$ & $66(23)$ & $61(22)$ & 0.21 \\
\hline Postoperative characteristics & & & \\
\hline Delirium & $1(1.1)$ & $5(12)$ & 0.015 \\
\hline Atrial fibrillation & $9(10)$ & $5(12)$ & $>0.99$ \\
\hline Myocardial infarction & $1(1.1)$ & $0(0.0)$ & $>0.99$ \\
\hline Surgical re-exploration & $2(2.3)$ & $0(0.0)$ & $>0.99$ \\
\hline $\begin{array}{l}\text { Deep sternal wound } \\
\text { infection }\end{array}$ & $2(2.3)$ & $0(0.0)$ & $>0.99$ \\
\hline & & & \\
\hline
\end{tabular}

Continued
Values are presented as $\mathrm{n}(\%)$ unless otherwise indicated. *Surgical time, CPB time and cross-clamp time in minutes.

BMI, Body Mass Index; CABG, coronary artery bypass grafting; $\mathrm{CPB}$, cardiopulmonary bypass; $\mathrm{DET}$, detection task; ICU, intensive care unit; IDN, identification task; LVEF, left ventricular ejection fraction; MCS, Mental Component Score; OCL, one card learning task; ONB, one back task; PCS, Physical Component Score; POCD, postoperative cognitive dysfunction.

should also assess functional status and work resumption alongside QoL to learn more about the impact of subtle changes in cognitive functioning on patients' daily lives.

Risk factors for a decreased QoL after CABG identified in this study are high baseline PCS and MCS, suggesting that patients with a good QoL before surgery are more likely to experience a decreased QoL after surgery, also known as regression to the mean. ${ }^{28}{ }^{30}$ Although not the primary outcome of our study, we found several significant differences between the groups with and without POCD. Age, education level and postoperative delirium have been identified as risk factors for POCD in other studies as well as in our study. ${ }^{617}$ Although our results indicate these variables as risk factors, our study groups are too small to reach for strong conclusions and should therefore be interpreted as hypothesis generating, or supportive of previous findings.

Our study has some important limitations. First, our patient selection might differ from other hospitals, which may limit generalisability, although we included only elective patients in our cohort and mortality risk was low, with a mean log EuroSCORE I of $3.8(\mathrm{SD} \pm 3)$. Second, it is likely that the early postoperative cognitive tests performed at 3 days after surgery were influenced by factors like sleep disturbance and opioids. We specifically chose day 3 for assessment of short-term POCD due to logistic reasons: many of our patients are transferred back to other hospitals on day 4 after surgery.

The main reasons to offer bypass surgery are to increase survival and symptom relief. Patient-reported outcomes like QoL and POCD are also important outcomes considered from the patients' perspective. Our study shows high incidences of long-term POCD and a decreased QoL 6 months after $\mathrm{CABG}$, which may negatively influence †ICU stay in hours. 
patients' daily lives. Studies addressing these topics can provide valuable information for patients, relatives and doctors regarding shared decision making.

Acknowledgements The authors thank all participating patients and involved students and research nurses. We specially thank Karin Havinga, who ensured data processing and management.

\section{Contributors FB, FK, ICCvdH, MFR, WD and MAM provided substantial} contributions to the conception and design of the work. FB, SH and ARA analysed and interpreted the data. FB drafted the work and all other authors revised the manuscript critically and approved the final version. All authors consented to the submission of this article. FB and MAM agreed to be accountable for all aspects of the work and ensured that questions related to the accuracy or integrity of any part of the will be appropriately investigated and resolved.

Funding The authors have not declared a specific grant for this research from any funding agency in the public, commercial or not-for-profit sectors.

Competing interests MAM received grants from AtriCure, Edwards, Abbott, Getinge and Stichting Beatrixoord, and has provided training for Livanova and Medtronic. ARA received grants from The Medicines Company, Rigel Inc, Orion and Carefusion/BD, and has received personal fees from Johnson \& Johnson, Ever Pharma, PAION and Philips.

Patient consent for publication Not required.

Ethics approval This study was approved by the local ethics committee (METC University Medical Center Groningen, 2018/226) and was conducted in agreement with the principles of the Declaration of Helsinki. Informed consent was obtained from all participants.

Provenance and peer review Not commissioned; externally peer reviewed.

Data availability statement All data relevant to the study are included in the article or uploaded as supplementary information. The data that support the findings in this study are available from the corresponding author (FB) on reasonable request.

Open access This is an open access article distributed in accordance with the Creative Commons Attribution 4.0 Unported (CC BY 4.0) license, which permits others to copy, redistribute, remix, transform and build upon this work for any purpose, provided the original work is properly cited, a link to the licence is given, and indication of whether changes were made. See: https://creativecommons.org/ licenses/by/4.0/.

\section{ORCID iD}

Fredrike Blokzill http://orcid.org/0000-0002-4120-761X

\section{REFERENCES}

1 Cloin ECW, Noyez L. Changing profile of elderly patients undergoing coronary bypass surgery. Neth Heart J 2005;13:132-8.

2 Markou ALP, van der Windt A, van Swieten HA, et al. Changes in quality of life, physical activity, and symptomatic status one year after myocardial revascularization for stable angina. Eur $J$ Cardiothorac Surg 2008;34:1009-15.

3 Eagle KA, Guyton RA, Davidoff R, et al. ACC/AHA guidelines for coronary artery bypass graft surgery: executive summary and recommendations. Circulation 1999;100:1464-80.

4 American Psychiatric Association. Diagnostic and statistical manual of mental disorders. 5th edn, 2013.

5 Evered L, Silbert B, Knopman DS, et al. Recommendations for the nomenclature of cognitive change associated with anaesthesia and surgery-2018. Br J Anaesth 2018;121:1005-12.

6 Selnes OA, Gottesman RF, Grega MA, et al. Cognitive and neurologic outcomes after coronary-artery bypass surgery. N Engl $\mathrm{J}$ Med 2012;366:250-7.

7 Kok WF, van Harten AE, Koene BMJA, et al. A pilot study of cerebral tissue oxygenation and postoperative cognitive dysfunction among patients undergoing coronary artery bypass grafting randomised to surgery with or without cardiopulmonary bypass*. Anaesthesia 2014;69:613-22.

8 Newman MF, Kirchner JL, Phillips-Bute B, et al. Longitudinal assessment of neurocognitive function after coronary-artery bypass surgery. N Engl J Med 2001;344:395-402.
9 Greaves D, Psaltis PJ, Ross TJ, et al. Cognitive outcomes following coronary artery bypass grafting: a systematic review and metaanalysis of 91,829 patients. Int $J$ Cardiol 2019;289:43-9.

10 von Elm E, Altman DG, Egger M, et al. The strengthening the reporting of observational studies in epidemiology (STROBE) statement: guidelines for reporting observational studies. Int J Surg 2014;12:1495-9.

11 Nederlandse Hart Registratie. Handboek Nederlandse Hartregistratie 2020, 2019. Available: www.nederlandsehartregistratie.nl [Accessed 17 Dec 2020].

12 Stevens PE, Levin A, Kidney Disease: Improving Global Outcomes Chronic Kidney Disease Guideline Development Work Group Members. Evaluation and management of chronic kidney disease: synopsis of the kidney disease: improving global outcomes 2012 clinical practice guideline. Ann Intern Med 2013;158:825.

13 Lang RM, Badano LP, Mor-Avi V, et al. Recommendations for cardiac chamber quantification by echocardiography in adults: an update from the American Society of Echocardiography and the European Association of Cardiovascular Imaging. Eur Heart J Cardiovasc Imaging 2015;16:233-71.

14 Fredrickson J, Maruff P, Woodward M, et al. Evaluation of the usability of a brief computerized cognitive screening test in older people for epidemiological studies. Neuroepidemiology 2010;34:65-75.

15 Falleti MG, Maruff P, Collie A, et al. Practice effects associated with the repeated assessment of cognitive function using the CogState battery at 10-minute, one week and one month test-retest intervals. J Clin Exp Neuropsychol 2006;28:1095-112.

16 Cogstate. Cogstate pediatric and adult normative data. Melbourne, Australia, 2018.

17 Kok WF, Koerts J, Tucha O, et al. Neuronal damage biomarkers in the identification of patients at risk of long-term postoperative cognitive dysfunction after cardiac surgery. Anaesthesia 2017;72:359-69.

18 Rasmussen LS, Larsen K, Houx P, et al. The assessment of postoperative cognitive function. Acta Anaesthesiol Scand 2001:45:275-89.

19 Hays RD, Morales LS. The RAND-36 measure of health-related quality of life. Ann Med 2001;33:350-7.

20 Koster S, Hensens AG, Oosterveld FGJ, et al. The delirium observation screening scale recognizes delirium early after cardiac surgery. Eur J Cardiovasc Nurs 2009;8:309-14.

21 Hartog J, Blokzijl F, Dijkstra S, et al. Heart Rehabilitation in patients awaiting Open heart surgery targeting to prevent Complications and to improve Quality of life (Heart-ROCQ): study protocol for a prospective, randomised, open, blinded endpoint (PROBE) trial. BMJ Open 2019;9:e031738

22 Thygesen K, Alpert JS, Jaffe AS, et al. Third universal definition of myocardial infarction. Eur Heart J 2012;33:2551-67.

23 Sacco RL, Kasner SE, Broderick JP, et al. An updated definition of stroke for the 21st century: a statement for healthcare professionals from the American Heart Association/American Stroke Association. Stroke 2013;44:2064-89.

24 Oldridge N, Höfer S, McGee H, et al. The HeartQoL: Part I. development of a new core health-related quality of life questionnaire for patients with ischemic heart disease. Eur J Prev Cardiol 2014;21:90-7.

25 van Harten AE, Scheeren TWL, Absalom AR. A review of postoperative cognitive dysfunction and neuroinflammation associated with cardiac surgery and anaesthesia. Anaesthesia 2012;67:280-93.

26 Rudolph JL, Schreiber KA, Culley DJ, et al. Measurement of postoperative cognitive dysfunction after cardiac surgery: a systematic review. Acta Anaesthesiol Scand 2010;54:663-77.

27 Abah U, Dunne M, Cook A, et al. Does quality of life improve in octogenarians following cardiac surgery? A systematic review. BMJ Open 2015;5:e006904

28 Blokzijl F, Houterman S, van Straten BHM, et al. Quality of life after coronary bypass: a multicentre study of routinely collected health data in the Netherlandst. Eur J Cardiothoracic Surg 2019;56:526-33.

29 Marasco SF, Sharwood LN, Abramson MJ. No improvement in neurocognitive outcomes after off-pump versus on-pump coronary revascularisation: a meta-analysis. Eur J Cardiothorac Surg 2008;33:961-70.

30 Shan L, Saxena A, McMahon R, et al. Coronary artery bypass graft surgery in the elderly: a review of postoperative quality of life. Circulation 2013;128:2333-43. 